Research Article

\title{
Research on Freight Development of Guangdong Province Based on Grey Theory Model
}

\author{
Lianhua Liu $\mathbb{D}^{1,2}$ Aili Xie $\mathbb{D}^{1}{ }^{1}$ and Hai Ping ${ }^{1}$ \\ ${ }^{1}$ Guangzhou Huashang College, Guangzhou 511300, Guangdong, China \\ ${ }^{2}$ Huashang Business Economic and Social Research Institute, Guangzhou 511300, Guangdong, China \\ Correspondence should be addressed to Aili Xie; ailixie16@126.com
}

Received 3 May 2021; Revised 1 June 2021; Accepted 19 June 2021; Published 21 July 2021

Academic Editor: Yiwen Zhang

Copyright (c) 2021 Lianhua Liu et al. This is an open access article distributed under the Creative Commons Attribution License, which permits unrestricted use, distribution, and reproduction in any medium, provided the original work is properly cited.

Logistics and economic development complement each other. The comprehensive competitiveness of Guangdong provincial economy ranks first in China. Under the influence of COVID-19, the freight development of Guangdong Province has been affected, but there is still lack of quantitative research. It is significant to explore the trend of economic development through the freight development of Guangdong Province. Based on the grey theory model, this paper uses six freight indexes to research freight development of Guangdong Province. Under the assumption that COVID-19 did not happen, we predicted the development value of freight index of Guangdong Province from January to December in 2020 and studied the influence based on the comparison between the predicted value and actual value. The empirical study shows three impact characteristics: stage characteristics, structural characteristics, and entity transmission characteristics. COVID-19 has a negative impact on the development of total freight volume, highway freight volume, waterway freight volume, and air freight volume in Guangdong Province. The influence values were $-23.001 \%,-29.344 \%,-11.296 \%$, and $-3.838 \%$. But, the freight volumes of railway and pipeline were positively affected by $14.343 \%$ and $13.057 \%$, respectively, due to their continuity and substitution to other transportation modes. To further explore the abate measures of COVID-19 impact on Guangdong's freight development, the grey correlation model is introduced to study the correlation factors of freight development of Guangdong Province. Through the research of the related factors, this paper puts forward some measures to promote the freight development of Guangdong Province in the postepidemic era.

\section{Introduction}

Guangdong Province is the South Gate of China, located in the South China Sea shipping hub position, since the Qin and Han Dynasties have become the starting point of the maritime Silk Road. The comprehensive competitiveness of Guangdong provincial economy ranks first in China. Since 1989, Guangdong's GDP has ranked first in China for 32 consecutive years, becoming the largest economic province in China. In 2020, Guangdong Province's GDP reached 11.08 trillion yuan, accounting for one-eighth of China's economy. The nine cities in the Pearl River Delta of Guangdong Province join hands with Hong Kong and Macao to build the bay area of Guangdong, Hong Kong, and Macao and become one of the four bay areas in the world side by side with New York Bay area, San Francisco Bay area, and Tokyo Bay area. The developments of economy and logistics complement each other. The rapid economic development of Guangdong Province promotes the improvement of logistics development level [1-4], which further supports the economic development of Guangdong Province.

The COVID-19 outbreak as a public health emergency has a negative impact on the economy from multiple channels. It also has a direct impact on the logistics economy. The epidemic situation affects the demand and supply of the logistics market. It affects the development of logistics enterprises through the operation of logistics and indirectly transmits to the field of logistics through the impact on domestic real economy and foreign trade. In the 
postepidemic period, the relevant supporting policies need a certain industry and time transmission, so COVID-19's impact on the logistics industry is characterized by multiple channels and multiple spatial and temporal superposition. Guangdong Province as an important node of the global supply chain, the total freight volume, road freight volume, railway freight volume, waterway freight volume, air freight volume, and pipeline freight volume has been affected by COVID-19.

In order to study the impact of COVID-19 on freight transportation in Guangdong Province and explore mitigation measures, this paper intends to use the grey prediction model GM $(1,1)$ to analyze the impact and introduce the grey correlation model to conduct a quantitative study on the correlation degree of the factors affecting the freight development of Guangdong Province. According to the correlation factors of the freight development of Guangdong Province, this paper puts forward some measures to promote the freight development of Guangdong Province in the postepidemic era.

\section{Literature Review}

2.1. Research Progress on Forecasting Freight Development. In recent years, logistics development prediction has become a hot issue for scholars. The methods commonly used by scholars include exponential smoothing [5-7], linear model [8], BP neural network method [5-9], multiple regression analysis $[5,9]$, seasonal autoregressive model [10-13], discrete wavelet technology [14], vector autoregressive method [15], and Markov chain theory [16], which are widely used in the prediction of logistics and freight development. In addition to conventional prediction methods, scholars also innovate prediction methods, such as a genetic algorithm and backpropagation (GA-BP) prediction model (optimized backpropagation neural network model using genetic algorithm), which are used to predict freight volume demand with small error [17]. Scholars use L-OD logistics demand forecasting method and construct a new model of double constraint gravity model to forecast logistics distribution, which achieves good forecasting effect. The state travel demand model (STDM) [18] is introduced to forecasting freight development, and a new hybrid multicriteria decision-making model combining Delphi, analytic network process (ANP), and quality function deployment (QFD) in fuzzy environment is applied to freight forecasting [19].

2.2. Application of GM in Forecasting Freight. Grey system theory is an effective method of studying and modeling systems consisting of small sample sizes that contain a limited amount of information and is widely used in many fields. The valuable information is extracted by processing the known information. This is further used to explore the evolution laws of the system and thus establish a prediction model. As there are many factors influencing the freight development of Guangdong Province, e.g., environmental factors of transportation and logistics, regional economic environment, government policy, and science and technology environment, it can be regarded as a grey system. Thus, it can be described using a grey model (GM). The GM $(1,1)$ is the most generally used grey model. GM $(1,1)$ used to predict the freight volume achieved satisfactory results $[5,9,20-24]$.

To sum up, the grey prediction model is widely used in logistics development and freight volume prediction. Therefore, it is scientific and feasible to use the grey prediction model in the quantitative research of Guangdong freight development:

(1) The innovation of this paper is the prediction of impact value refined to month which is a more precise observation of COVID-19's impact on Guangdong's freight development.

(2) Practical significance: through quantitative and accurate research on the monthly impact value of freight development in Guangdong Province, we can grasp the situation of economic operation in Guangdong Province from the side and promote the formulation and implementation of relevant economic stimulus policies, which has certain management practical significance.

\section{Research Methods}

3.1. Introduction of $G M(1,1)$. The differential equation of grey system theory is called GM. G stands for grey, $M$ stands for model, and $\operatorname{GM}(1,1)$ is a one-order and one-variable differential equation model. The modeling process and mechanism of GM $(1,1)$ are as follows:

$$
X^{(0)}=\left\{x^{(0)}(1), x^{(0)}(2), x(3), \ldots, x^{(0)}(n)\right\}
$$

(1) Record the original data sequence as a nonnegative sequence, where $X^{(0)}$ is a nonnegative sequence, $X^{(0)}(k) \geq 0, k=1,2, \ldots, n$.

(2) Generate a cumulative data sequence $X^{(1)}$ :

$$
X^{(1)}=\left\{x^{(1)}(1), x^{(1)}(2), x^{(1)}(3), \ldots, x^{(1)}(n)\right\},
$$

where $x^{(1)}(k)=\sum_{i=1}^{k} x^{(0)}(i), k=1,2, \ldots, n . \quad Z^{(1)}$ is the adjacent mean generating sequence of $X^{(1)}$ :

$$
\begin{aligned}
& Z^{(1)}=\left\{z^{(1)}(1), z^{(1)}(2), z^{(1)}(3), \ldots, z^{(1)}(n)\right\}, \\
& \text { where } Z^{(1)} \quad(k)=0.5 x^{(1)}(k)+\quad 0.5 x^{(1)}(k-1), \\
& k=1,2, \ldots, n .
\end{aligned}
$$

(3) Establish GM $(1,1)$ :

$$
x^{(0)}(k)+a Z^{(1)}(k)=b .
$$

in which "a" and " $b$ " are parameters, which are development grey number and endogenous control grey number, respectively.

(4) Solve the parameters "a" and "b":

If $a=(a b)^{T}$ is a parameter column and 


$$
\begin{aligned}
& Y=\left[\begin{array}{c}
x^{(0)}(2) \\
x^{(0)}(3) \\
\vdots \\
x^{(0)}(N)
\end{array}\right], \\
& B=\left[\begin{array}{cc}
z^{(1)}(2) & 1 \\
z^{(1)}(3) & 1 \\
\vdots & \vdots \\
z^{(1)}(n) & 1
\end{array}\right],
\end{aligned}
$$

then find the least square estimation coefficient sequence of differential equation $x^{(0)}(k)+$ $a z^{(1)}(k)=b$, satisfying condition $\widehat{a}=\left(B^{T} B\right)^{-1} B^{T} Y$.

(5) Establish a prediction model.

Establish the whitening equation corresponding to the grey differential equation, as the following formula:

$$
\frac{\mathrm{d} x^{(1)}}{\mathrm{d} t}+a x^{(1)}=b \text {. }
$$

As mentioned above, the time response sequence of GM $(1,1)$ grey differential equation $x^{(0)}(k)+a z^{(1)}(k)=b$ is the following formula:

$$
\hat{x}^{(1)}(k+1)=\left(x^{(0)}(1)-\frac{b}{a}\right) e^{-a k}+\frac{b}{a}, \quad k=1,2,3, \ldots, n .
$$

The predicted values generated by restoration are as follows:

$$
\widehat{x}^{(0)}(k+1)=\widehat{x}^{(1)}(k+1)-\widehat{x}^{(1)}(k), \quad k=1,2,3, \ldots, n .
$$

\subsection{Grey Prediction Model $(G M(1,1))$ Test}

3.2.1. Modeling Rationality Test. Firstly, the modeling rationality of the original sequence $x^{(0)}$ is tested, and the grade $\operatorname{ratio} \lambda(k)$ is used to represent

$$
\lambda(k)=\frac{x^{(0)}(k+1)}{x^{(0)}(k)},
$$

where $k=1,2,3, \ldots, n$. When all $\lambda(k) \in\left(e^{-(2 / n+1)}, e^{(2 / n+1,)}\right)$, the GM $(1,1)$ can be used in the $x^{(0)}$ series for satisfactory prediction modeling.

\subsubsection{Grey System Model Prediction Accuracy Test}

(1) Residual Error Test. After modeling with GM $(1,1)$, the predicted value sequence is as follows:

$$
\widehat{X}^{(0)}(K)=\left\{\widehat{x}^{(0)}(1), \widehat{x}^{(0)}(1), \ldots, \hat{x}^{(0)}(n)\right\} .
$$

By calculating the series $X^{(0)}(K)$ and $\hat{x}^{(0)}(K)$, the following $\mathrm{GM}(1,1)$ modeling rationality residual test index is obtained.
(1) Absolute residual is

$$
\varepsilon(k)=x^{(0)}(k)-\hat{x}^{(0)}(k) .
$$

(2) Relative residual is

$$
\Delta(k)=\left|\frac{\varepsilon(k)}{x^{(0)}(k)}\right|
$$

(3) Average residual is

$$
\overline{\Delta(k)}=\frac{1}{n} \sum_{i=1}^{n} \Delta(k)
$$

(4) Average accuracy is

$$
\rho^{0}=(1-\overline{\Delta(k)}) \times 100 \% .
$$

Residual test standards are as shown in Table 1.

(2) Posterior Variance Test. Suppose $X^{(0)}$ is the original sequence, $\widehat{X}^{(0)}$ is the simulation error sequence, and $\varepsilon^{0}$ is the absolute residual sequence. Test standards are shown in Table 1.

(1) Mean value of $X^{(0)}$ is

$$
\bar{x}=\frac{1}{n} \sum_{k=1}^{n} x^{(0)}(k) \text {. }
$$

(2) Variance of $X^{(0)}$ is

$$
S_{1}=\sqrt{\frac{1}{n} \sum_{k=1}^{n}\left(x^{(0)}(k)-\bar{x}\right)^{2}}
$$

(3) Mean of absolute residuals is

$$
\bar{\varepsilon}=\frac{1}{n} \sum_{k=1}^{n} \varepsilon(k) .
$$

(4) Absolute residual variance is

$$
S_{2}=\sqrt{\frac{1}{n} \sum_{k=1}^{n}(\varepsilon(k)-\bar{\varepsilon})^{2}} .
$$

(5) Ratio of variance is

$$
C=\frac{S_{2}}{S_{1}} .
$$

(6) Probability of small error is

$$
\begin{aligned}
P & =p\left(|\varepsilon(k)-\bar{\varepsilon}|<0.6745 S_{1}\right), \\
S_{0} & =0.6745 S_{1} .
\end{aligned}
$$

3.3. Grey Correlation Degree. Correlation degree refers to the measurement of the correlation between the factors of the 
TABLE 1: Grade reference table of grey system model parameters.

\begin{tabular}{lcccc}
\hline Accuracy class & Relative residuals $(\Delta(k))$ & Mean variance ratio $(C)$ & Probability of small error $(P)$ & Correlation degree $\left(\gamma_{0 i}\right)$ \\
\hline Good & 0.01 & 0.35 & 0.95 & 0.90 \\
Qualification & 0.05 & 0.45 & 0.85 & 0.80 \\
Barely qualified & 0.1 & 0.50 & 0.70 & 0.70 \\
Disqualification & 0.2 & 0.65 & 0.70 & 0.60 \\
\hline
\end{tabular}

two systems that change with time or different objects. Grey system theory puts forward the concept of grey correlation analysis for each subsystem and intends to seek the numerical relationship between each subsystem in the system through certain methods or measure the influence of each subfactor in the system on the main factor. Grey correlation analysis provides a quantitative measurement for the development and change trend of a system, which is suitable for dynamic process analysis. follows:

The calculation steps of grey correlation degree are as

(1) Establish a raw data matrix $X_{i}$ for each index:

$$
X_{i}=\left(x_{i}(1), x_{i}(2), \ldots, x_{i}(k)\right) \text {. }
$$

Here, $x_{i}(k)$ represents the original data of $i$ factor in year $k$.

(2) Calculate initialization transformation of matrix $X_{i}^{\prime}$ :

$$
X_{i}^{\prime}=\left(\frac{x_{i}(1)}{x_{i}(1)}, \frac{x_{i}(2)}{x_{i}(1)}, \ldots, \frac{x_{i}(k)}{x_{i}(1)}\right)=\left(x_{i}^{\prime}(1), x_{i}^{\prime}(2), \ldots, x_{i}^{\prime}(k)\right) \text {. }
$$

(3) Calculate the difference sequence $\Delta_{0 i}(k)$. The difference sequence occurs between the main factor sequence data and the measure factors:

$$
\begin{aligned}
& \Delta_{0 i}(k)=\left|x_{0}(k)-x_{i}^{\prime} k\right|, \quad k=1,2, \ldots, n, i=1,2, \ldots, m, \\
& \Delta_{0 i}(k)=\left(\Delta_{0 i}(1), \Delta_{0 i}(2), \ldots, \Delta_{0 i}(k)\right) .
\end{aligned}
$$

(4) The correlation coefficient $\xi_{0 i}(k)$ and grey correlation degree $\gamma_{0 i}$ are calculated:

$$
\xi_{0 i}(k)=\frac{\min _{i} \min _{k} \Delta_{0 i}(k)+\phi \max _{i} \max _{k} \Delta_{0 i}(k)}{\Delta_{0 i}(k)+\phi \max _{i} \max _{k} \Delta_{0 i}(k)},
$$

where $\varphi$ is the resolution coefficient, which improves the significance of the difference between the correlation coefficients, $\varphi \in(0,1)$, and the general value is 0.5 . The grey correlation degree is shown as follows:

$$
\gamma_{0 i}=\frac{1}{n} \sum_{k=1}^{n} \xi_{0 i}(k)
$$

In summary, the relevant parameters of the grey system model level index [20] reference table are shown in Table 1 .

\section{Construction of GM $(1,1)$}

4.1. Data Source and Description. The data are from the monthly open statistics of Guangdong Provincial Bureau of Statistics from 2013 to 2020 . The data content includes six groups of data: total freight volume, truck freight volume, railway freight volume, waterway freight volume, air freight volume, and pipeline freight volume of Guangdong Province. For the convenience of calculation, total freight volume, railway freight volume, truck freight volume, water freight volume, air cargo volume, and pipeline freight volume are expressed. The annual freight development of Guangdong Province is counted, covering the six freight indexes. The original data to predict the development of freight of Guangdong Province in 2020 are shown in Table 2 .

4.2. Rationality of $G M(1,1)$ Construction. The rationality of model construction was tested in advance. On the basis of the original data sequence, the stage ratio $\lambda(k)$ is calculated according to formula (10).

4.2.1. Calculation of the Grade Ratio $\lambda(k)$. The grade ratio is calculated as follows:

$$
\begin{aligned}
\lambda(k) F & =(0.8486,0.9526,1.0130,0.9395,0.9341,0.9565), \\
\lambda(k) R & =(1.0918,1.0776,0.9792,1.4029,0.9753,0.9478), \\
\lambda(k) T & =(0.8256,0.9319,1.0372,0.9450,0.9423,0.9595), \\
\lambda(k) W & =(0.8813,1.0004,0.9421,0.8827,0.9175,0.9445), \\
\lambda(k) A & =(0.9167,0.9730,0.9250,0.9697,0.7466,0.9325), \\
\lambda(k) P & =(0.9420,1.0599,0.9699,0.9663,0.8258,1.0042) .
\end{aligned}
$$

4.2.2. Judgment of the Grade Ratio. $\lambda(k) \in\left(e^{-(2 / n+1)}\right.$, $\left.e^{(2 / n+1)}\right)$, when $n=7, \lambda(k) \in(0.7788,1.2840)$. If $\lambda(\mathrm{k})$ in the above range, $x^{(0)}(k)$ is suitable for GM $(1,1) . \lambda(k) F \in$ $(0.8486,1.0130), \lambda(k) T \in(0.8256,1.0372), \lambda(k) W \in$ $(0.8813,1.0004)$, and $\lambda(k) \quad P \in(0.8258,1.0559)$, where $k$ $=2,3,4,5,6,7$, and the grade ratios are in $(0.7788,1.2840)$; hence, $X_{F}^{0} X_{T}^{0}, X_{W}^{0}$, and $X_{P}^{0}$ can be modeled by GM $(1,1)$. The values of grey development coefficient " $a$ " are 0.0429 , $0.0364,0.0752$, and 0.0539 , respectively, i.e., less than 0.3 , which are suitable for medium- and long-term prediction.

However, $\lambda(k) R \in(0.9478,1.4029)$ and $\lambda(k) A \in(0.7446,1.0442)$. There is a grade ratio not in the region, which is not available 
TABle 2: Monthly data of freight indicators of Guangdong Province from 2013 to 2020 (unit: million tons) (\%).

\begin{tabular}{|c|c|c|c|c|c|c|c|c|c|c|c|}
\hline \multirow[t]{2}{*}{ Year } & \multirow[t]{2}{*}{ Total freight volume $(F)$} & \multicolumn{2}{|c|}{$\begin{array}{c}\text { Railway freight } \\
\text { volume }(R)\end{array}$} & \multicolumn{2}{|c|}{$\begin{array}{l}\text { Truck freight } \\
\text { volume }(T)\end{array}$} & \multicolumn{2}{|c|}{$\begin{array}{l}\text { Water freight } \\
\text { volume }(W)\end{array}$} & \multicolumn{2}{|c|}{$\begin{array}{c}\text { Air cargo } \\
\text { volume }(A)\end{array}$} & \multicolumn{2}{|c|}{$\begin{array}{l}\text { Pipeline freight } \\
\text { volume }(P)\end{array}$} \\
\hline & & Amount & Ratio & Amount & Ratio & Amount & Ratio & Amount & Ratio & Amount & Ratio \\
\hline 2013 & 3065.44 & 122.38 & 3.992 & 2176.43 & 70.999 & 688.51 & 22.460 & 1.32 & 0.043 & 76.81 & 2.506 \\
\hline 2014 & 3612.49 & 112.09 & 3.103 & 2636.19 & 72.974 & 781.25 & 21.626 & 1.44 & 0.040 & 81.54 & 2.257 \\
\hline 2015 & 3792.21 & 104.02 & 2.743 & 2828.87 & 74.597 & 780.93 & 20.593 & 1.48 & 0.039 & 76.93 & 2.029 \\
\hline 2016 & 3743.48 & 106.23 & 2.838 & 2727.37 & 72.857 & 828.93 & 22.143 & 1.60 & 0.043 & 79.32 & 2.119 \\
\hline 2017 & 3984.69 & 75.72 & 1.900 & 2886.19 & 72.432 & 939.04 & 23.566 & 1.65 & 0.041 & 82.09 & 2.060 \\
\hline 2018 & 4265.78 & 77.64 & 1.820 & 3063.04 & 71.805 & 1023.51 & 23.994 & 2.21 & 0.052 & 99.41 & 2.330 \\
\hline 2019 & 4459.75 & 81.92 & 1.837 & 3192.31 & 71.580 & 1083.71 & 24.300 & 2.37 & 0.053 & 98.99 & 2.220 \\
\hline 2020 & 3547.51 & 77.67 & 2.189 & 2313.56 & 65.216 & 1036.57 & 29.220 & 2.38 & 0.067 & 117.35 & 3.308 \\
\hline
\end{tabular}

Data source: according to the website data of Guangdong Provincial Bureau of Statistics.

for $X_{R}^{(0)}$ and $X_{A}^{(0)}$ modeled in $\mathrm{GM}(1,1)$ directly. Therefore, it is necessary to do translation transformation on the data, and the translated data are $X_{R}^{(0)^{\prime}}$ and $X_{A}^{(0)^{\prime}}$, as follows:

$X_{R}^{(0)^{\prime}}=(202.38,192.09,184.02,186.23,155.72,157.64,161.92)$,

$X_{A}^{(0)^{\prime}}=(2.12,2.24,2.28,2.40,2.45,3.01,3.17)$.

The grade ratios of $X_{R}^{(0)^{\prime}}$ and $X_{A}^{(0)^{\prime}}$ are calculated:

$\lambda^{\prime}(k) R=(1.0536,1.0439,0.9881,1.1959,0.9878,0.9736)$,

$\lambda^{\prime(k)} R \in(0.9736,1.1959), \quad K=2,3,4,5,6,7$,

$\lambda^{\prime}(k) A=(0.9464,0.9825,0.9500,0.9796,0.8140,0.9495)$,

$\lambda^{\prime}(k) A \in(0.8140,0.9825), \quad K=2,3,4,5,6,7$.
The grade ratios of $X_{R}^{0}$ and $X_{A}^{0}$ are in the rank of $\lambda(k)$ and $\epsilon(0.7788,1.2840)$. The values of grey development coefficient " $-a$ " are -0.0435 and -0.0784 , which are less than 0.3. So $X_{R}^{b}$ and $X_{A}^{b}$ are suitable for medium- and long-term prediction.

4.3. Construction of $G M(1,1)$. According to the original sequence, the accumulated sequence is generated and the differential equation is constructed. On the basis of solving the values of "a" and " $b$," the time response sequence is obtained, as formulas (30)-(35). The predicted values are calculated according to the time response sequence, shown in Tables 3 and 4.

$$
\begin{gathered}
\widehat{X}^{(1)}(k+1)_{F}=\left(X^{(0)}(1)_{F}-\frac{b}{a}\right) e^{-a k}+\frac{b}{a}=81237.44 e^{0.0429 k}-78172.00, \\
\widehat{X}^{(1)}(k+1)_{R}=\left(X^{(0)_{1}}(1)_{R}-\frac{b}{a}\right) e^{-a k}+\frac{b}{a}=4713.89-4511.51 e^{-0.0435 k}, \\
\widehat{X}^{(1)}(k+1)_{T}=\left(X^{(0)}(1)_{T}-\frac{b}{a}\right) e^{-a k}+\frac{b}{a}=71059.66 e^{0.03637 k}-6888311.00, \\
\widehat{X}^{(1)}(k+1)_{W}=\left(X^{(0)}(1)_{W}-\frac{b}{a}\right) e^{-a k}+\frac{b}{a}=9522.20 e^{0.0752 k}-8833.69 \\
\widehat{X}^{(1)}(k+1)_{A}=\left(X^{(0) \prime}(1)_{A}-\frac{b}{a}\right) e^{-a k}+\frac{b}{a}=25.8654 e^{0.0784 k}-23.7454, \\
\widehat{X}^{(1)}(k+1)_{P}=\left(X^{(0)}(1)_{P}-\frac{b}{a}\right) e^{-a k}+\frac{b}{a}=1357.82 e^{0.0539 k}-1281.01 .
\end{gathered}
$$

4.4. Validation of Modeling Accuracy of GM $(1,1)$ of Freight Volume in Guangdong Province. According to the modeling results of GM $(1,1)$, we will test the accuracy of the model by the residual test and posterior test. 
TABLE 3: Actual value and forecast value of the freight development index in Guangdong Province (unit: million tons).

\begin{tabular}{|c|c|c|c|c|c|c|}
\hline \multirow[t]{2}{*}{ Year } & \multicolumn{2}{|c|}{$\begin{array}{l}\text { Total freight } \\
\text { volume }(F)\end{array}$} & \multicolumn{2}{|c|}{$\begin{array}{c}\text { Railway freight } \\
\text { volume }(R)\end{array}$} & \multicolumn{2}{|c|}{$\begin{array}{l}\text { Truck freight } \\
\text { volume }(T)\end{array}$} \\
\hline & $X_{F}^{0}$ & $\widehat{X}_{F}$ & $X_{R}^{b}$ & $\widehat{X}_{R}$ & $X_{T}^{b}$ & $\widehat{X}_{T}$ \\
\hline 2013 & 3065.44 & 3065.44 & 202.38 & 202.38 & 2176.43 & 2176.55 \\
\hline 2014 & 3612.49 & 3561.51 & 192.09 & 192.04 & 2636.19 & 2632.37 \\
\hline 2015 & 3792.21 & 3717.65 & 184.02 & 183.87 & 2828.87 & 2729.88 \\
\hline 2016 & 3743.48 & 3880.63 & 186.23 & 176.04 & 2727.37 & 2831.01 \\
\hline 2017 & 3984.69 & 4050.76 & 155.72 & 168.55 & 2886.19 & 2935.88 \\
\hline 2018 & 4265.78 & 4228.35 & 157.64 & 161.37 & 3063.04 & 3044.64 \\
\hline 2019 & 4459.75 & 4413.72 & 161.92 & 154.50 & 3192.31 & 3157.43 \\
\hline
\end{tabular}

Source: according to the calculation criteria.

4.4.1. Residual Test. The residual test is carried out to test the accuracy of GM $(1,1)$ in forecasting the freight volume of Guangdong Province. The predicted value of total freight volume, railway freight volume, truck freight volume, water freight volume, air cargo volume, and pipeline freight volume is compared with the original data. $\varepsilon(k)_{F}, \varepsilon(k)_{R}, \varepsilon(k)_{T}$, $\varepsilon(k)_{W}, \varepsilon(k)_{A}$, and $\varepsilon(k)_{P}$ and $\Delta(k)_{F}, \Delta(k)_{R}, \Delta(k)_{T}, \Delta(k)_{W}$, $\Delta(k)_{A}$, and $\Delta(k)_{P}$ are calculated according to formulas (11)-(14), and the results are shown in Tables 5 and 6.

$$
\begin{aligned}
& \Delta(k)_{F} \leq 0.05 \text {, } \\
& \overline{\Delta(k)_{F}}=0.0152<0.05 \text {, } \\
& \rho_{F}^{0}=\left(1-\overline{\Delta(k)_{F}}\right) * 100 \%=98.48 \%>90 \%, \\
& \Delta(k)_{R} \leq 0.05 \text {, } \\
& \overline{\Delta(k)_{R}}=0.0297<0.05 \text {, } \\
& \rho_{R}^{0}=\left(1-\overline{\Delta(k)_{R}}\right) * 100 \%=97.03 \%>90 \%, \\
& \Delta(k)_{T} \leq 0.05 \text {, } \\
& \overline{\Delta(k)_{T}}=0.0155<0.05 \text {, } \\
& \rho_{T}^{0}=\left(1-\overline{\Delta(k)_{T}}\right) * 100 \%=98.45 \%>90 \%, \\
& \Delta(k)_{W} \leq 0.05 \text {, } \\
& \overline{\Delta(k)_{W}}=0.02548<0.05 \text {, } \\
& \rho_{W}^{0}=\left(1-\overline{\Delta(k)_{W}}\right) * 100 \%=97.96 \%>90 \%, \\
& \Delta(k)_{A} \leq 0.05 \text {, } \\
& \overline{\Delta(k)_{A}}=0.0359<0.05 \text {, } \\
& \rho_{A}^{0}=\left(1-\overline{\Delta(k)_{A}}\right) * 100 \%=96.41 \%>90 \%, \\
& \Delta(k)_{P} \leq 0.05 \text {, } \\
& \overline{\Delta(k)_{P}}=0.0441<0.05 \text {, } \\
& \rho_{P}^{0}=\left(1-\overline{\Delta(k)_{C}}\right) * 100 \%=95.59 \%>90 \% .
\end{aligned}
$$

\begin{tabular}{|c|c|c|c|c|c|c|}
\hline \multirow[t]{2}{*}{ Year } & \multicolumn{2}{|c|}{$\begin{array}{l}\text { Water freight } \\
\text { volume }(W)\end{array}$} & \multicolumn{2}{|c|}{$\begin{array}{c}\text { Air cargo } \\
\text { volume }(A)\end{array}$} & \multicolumn{2}{|c|}{$\begin{array}{l}\text { Pipeline } \\
\text { freight volume } \\
(P)\end{array}$} \\
\hline & $X_{W}^{0}$ & $\widehat{X}_{W}$ & $X_{A}^{0}$ & $\widehat{X}_{A}$ & $X_{P}^{0}$ & $\widehat{X}_{P}$ \\
\hline 2013 & 688.51 & 688.51 & 2.12 & 2.12 & 76.81 & 76.81 \\
\hline 2014 & 781.25 & 744. & 2.24 & 2.11 & 81.54 & 75.14 \\
\hline 2015 & 780.93 & 802.20 & 2.28 & 2.28 & 76.93 & 79.29 \\
\hline 2016 & 828.93 & 864.88 & 2.40 & 2.47 & 79.32 & 83.68 \\
\hline 2017 & 939.04 & 932.46 & 2.45 & 2.67 & 82.09 & 88.31 \\
\hline 2018 & 1023.51 & 1005.32 & 3.01 & 2.89 & 99.41 & 93.20 \\
\hline 2019 & 1083.71 & 1083.88 & 3.017 & 3.12 & 98.99 & 98.35 \\
\hline
\end{tabular}

To sum up, GM $(1,1)$ has a good accuracy in modeling and forecasting the freight development index of Guangdong Province and can pass the residual test.

4.4.2. Posterior Error Test. In order to further test the accuracy of GM $(1,1)$ in forecasting the development of freight
TABLE 4: Actual value and forecast value of the freight development index in Guangdong Province (unit: million tons).

Source: according to the calculation criteria.

TABLE 5: Residual test results of GM $(1,1)$ of freight volume in Guangdong Province.

\begin{tabular}{ccccccc}
\hline & \multicolumn{2}{c}{ Total freight } & \multicolumn{2}{c}{$\begin{array}{c}\text { Railway freight } \\
\text { volume }(R)\end{array}$} & \multicolumn{2}{c}{ Truck freight } \\
volume $(T)$ \\
& $\varepsilon(k)_{F}$ & $\Delta(k)_{F}$ & $\varepsilon(k)_{R}$ & $\Delta(k)_{R}$ & $\varepsilon(k)_{T}$ & $\Delta(k)_{T}$ \\
\hline 2013 & 0.000 & 0.000 & 0.000 & 0.000 & 0.120 & 0.000 \\
2014 & -50.980 & 0.014 & -0.050 & 0.000 & -3.820 & 0.001 \\
2015 & -74.560 & 0.020 & -0.150 & 0.001 & -98.990 & 0.035 \\
2016 & 137.150 & 0.037 & -10.190 & 0.055 & 103.640 & 0.038 \\
2017 & 66.070 & 0.017 & 12.830 & 0.082 & 49.690 & 0.017 \\
2018 & -37.430 & 0.009 & 3.730 & 0.024 & -18.400 & 0.006 \\
2019 & -46.030 & 0.010 & -7.420 & 0.046 & -34.880 & 0.011 \\
\hline
\end{tabular}

Source: according to the calculation criteria.

TABLE 6: Residual test results of GM $(1,1)$ of freight volume in Guangdong Province.

\begin{tabular}{ccccccc}
\hline & \multicolumn{2}{c}{$\begin{array}{c}\text { Water freight } \\
\text { vear }\end{array}$} & \multicolumn{2}{c}{ Air cargo } & \multicolumn{2}{c}{ Pipeline freight } \\
& $\varepsilon(k)_{W}$ & $\Delta(k)_{W}$ & $\varepsilon(k)_{A}$ & $\Delta(k)_{A}$ & $\varepsilon(k)_{P}$ & $\Delta(k)_{P}$ \\
\hline 2013 & 0.000 & 0.000 & 0.000 & 0.000 & 0.000 & 0.000 \\
2014 & -37.190 & 0.048 & -0.130 & 0.058 & -0.078 & 0.078 \\
2015 & 21.270 & 0.027 & 0.000 & 0.000 & 0.031 & 0.031 \\
2016 & 35.950 & 0.043 & 0.070 & 0.029 & 0.055 & 0.055 \\
2017 & -6.580 & 0.007 & 0.220 & 0.090 & 0.076 & 0.076 \\
2018 & -18.190 & 0.018 & -0.120 & 0.040 & -0.062 & 0.062 \\
2019 & 0.170 & 0.000 & 0.103 & 0.034 & -0.006 & 0.006
\end{tabular}

Source: according to the calculation criteria.

volume in Guangdong Province, a posteriori test is carried out. According to formulas (15)-(18), the original sequence's variance of $X_{F}^{0}, X_{R}^{0}, X_{T}^{0}, X_{W}^{0}, X_{A}^{0}$, and $X_{P}^{0}$ is calculated, and the results are as follows:

$$
\begin{aligned}
& S_{1 F}=456.316, \\
& S_{1 R}=18.535, \\
& S_{1 T}=329.434, \\
& S_{1 W}=143.907, \\
& S_{1 A}=0.365, \\
& S_{1 P}=9.902 .
\end{aligned}
$$


The absolute residual sequence's variance of $\varepsilon(k)_{F}$, $\varepsilon(k)_{R}, \varepsilon(k)_{T}, \varepsilon(k)_{W}, \varepsilon(k)_{A}$, and $\varepsilon(k)_{p}$ is calculated, and the results are as follows:

$$
\begin{aligned}
S_{2 F} & =76.211, \\
S_{2 R} & =7.497, \\
S_{2 T} & =64.003, \\
S_{2 W} & =24.194, \\
S_{2 A} & =0.124, \\
S_{2 P} & =4.885 .
\end{aligned}
$$

According to formula (19), calculate the ratio of variance of the freight index. The results are as follows:

$$
\begin{aligned}
C_{F} & =0.167, \\
C_{R} & =0.404, \\
C_{T} & =0.194, \\
C_{W} & =0.168, \\
C_{A} & =0.365, \\
C_{P} & =0.493 .
\end{aligned}
$$

$C_{P}$ is less than 0.5 , so the posterior error test is barely qualified. $C_{R}$ and $C_{A}$ are greater than 0.35 and less than 0.45 , respectively, and the posterior error test result is qualified. $C_{F}, C_{T}$, and $C_{W}$ are less than 0.35 , and hence, the posterior error test result is good.

Calculate the probability of small error according to formulas (20) and (21). The results are as follows:

$$
\begin{aligned}
S_{0 F} & =307.785, \\
S_{0 R} & =12.502, \\
S_{0 T} & =222.203, \\
S_{0 W} & =97.065, \\
S_{0 A} & =0.246, \\
S_{0 P} & =6.679, \\
\left|\varepsilon(k)_{F}-\bar{\varepsilon}_{F}\right| & =(0.826,50.154,73.734,137.976,66.896,36.604,45.204), \quad P=1>0.95, \\
\left|\varepsilon(k)_{R}-\bar{\varepsilon}_{R}\right| & =(0.179,0.129,0.029,10.011,13.009,3.909,7.241), \quad P=85.7>0.8, \\
\left|\varepsilon(k)_{T}-\bar{\varepsilon}_{T}\right| & =(0.497,3.443,98.613,104.017,50.067,18.023,34.503), \quad P=1>0.95, \\
\left|\varepsilon(k)_{W}-\bar{\varepsilon}_{W}\right| & =(0.653,36.537,21.923,36.603,5.927,17.537,0.823), \quad P=1>0.95 \\
\left|\varepsilon(k)_{A}-\bar{\varepsilon}_{A}\right| & =(0.020,0.150,0.020,0.050,0.200,0.140,0.083), \quad P=1>0.95, \\
\left|\varepsilon(k)_{P}-\bar{\varepsilon}_{P}\right| & =(0.044,6.356,2.404,4.404,6.264,6.166,0.596), \quad P=1>0.95 .
\end{aligned}
$$

To sum up, the six indicators of freight development in Guangdong Province, total freight volume, railway freight volume, truck freight volume, water freight volume, air cargo volume, and pipeline freight volume, all meet the requirements of posterior error test standard $C<0.5,0.8<P$, which indicate that the accuracy of the model is qualified.

\section{Impact of COVID-19 on Freight Development of Guangdong Province}

The results of the rationality test of model construction, residual test, and posteriori test proved that GM $(1,1)$ is feasible to forecast the freight development of Guangdong
Province in 2020. Due to the particularity of railway transportation and air transportation, after eliminating the influence of $C$ value, the prediction results are shown in Table 7.

In order to reflect COVID-19's monthly impact on Guangdong Province's freight development, further explore the monthly forecast value of freight volume in Guangdong Province of 2020:

(1) Calculate the ratio of each month in different years to the freight volume of that year.

Record the freight development data of Guangdong Province from 2013 to 2019 as matrix of $A_{F 7 \times 12}$, 
Table 7: Forecast freight volume value of Guangdong Province in 2020 (unit: million ton).

\begin{tabular}{lcccccc}
\hline Year & $\begin{array}{c}\text { Total freight } \\
\text { volume }\end{array}$ & $\begin{array}{c}\text { Railway freight } \\
\text { volume }\end{array}$ & $\begin{array}{c}\text { Truck, freight } \\
\text { volume }\end{array}$ & $\begin{array}{c}\text { Water freight } \\
\text { volume }\end{array}$ & $\begin{array}{c}\text { Air cargo } \\
\text { volume }\end{array}$ & $\begin{array}{c}\text { Pipeline freight } \\
\text { volume }\end{array}$ \\
\hline 2020 & 4607.222 & 67.927 & 3274.392 & 1168.572 & 2.475 & 103.797 \\
\hline
\end{tabular}

Source: according to the calculation criteria.

$A_{R 7 \times 12}, A_{T 7 \times 12}, A_{W 7 \times 12}, A_{A 7 \times 12}$, and $A_{P 7 \times 12}$, and calculate the ratio of monthly freight volume $\left(a_{k j}\right)$ to the total freight volume of the year $\left(x^{(0)}(k)\right)$ and record it as $R_{k j}$, where $R$ is ratio, $k$ is year, and $j$ is month:

$$
R_{k j}=\frac{a_{k j}}{x^{(0)}(k)}, \quad k=1,2,3, \ldots, 7, j=1,2,3, \ldots, 12 .
$$

(2) Calculate the average freight ratio of the same month in different years:

$$
\overline{R_{j}}=\frac{1}{7} \sum_{k=1}^{7} r_{k j}, \quad k=1,2,3, \ldots, 7, j=1,2,3, \ldots, 12 \text {. }
$$

According to formulas (35)-(41), we can calculate $\overline{R_{j F}}, \overline{R_{j R}}, \overline{R_{j T}}, \overline{R_{j W}}, \overline{R_{j A}}$, and $\overline{R_{j P}}$ from January to December, as shown in Table 8.

(3) Calculate monthly forecast value as follows:

$$
\widehat{a}_{k j}=\bar{R}_{j} \widehat{x}^{(0)} k \quad k=1,2,3, \ldots, 9, j=1,2,3, \ldots, 12 .
$$

(4) Calculate the influence value I as follows:

$$
\begin{aligned}
I_{k j} & =\frac{\left(a_{k j}-\widehat{a}_{i j}\right)}{\widehat{a}_{i j}} \times 100 \%, \\
I_{k} & =\frac{\left(x^{(0)}(k)-\hat{x}^{(0)} k\right)}{\hat{x}^{(0)} k} \times 100 \% .
\end{aligned}
$$

According to formulas (41)-(45), the monthly forecast value and impact of freight development in Guangdong Province from January to December 2020 are calculated, as shown in Tables 9 and 10 and Figure 1.

According to Tables 9 and 10 and Figure 1, reflecting the influence of COVID-19, there are three characteristics of freight transport development of Guangdong Province in 2020, which are stage characteristics, structural characteristics, and entity conduction.

5.1. Stage Characteristics. The first stage is the direct impact stage. Freight transport in Guangdong Province is stagnant during January and February. Affected by the epidemic situation, most logistics enterprises shut down except emergency logistics, and some logistics transportation channels were interrupted. The risk mainly comes from the disconnection of logistics supply and demand and the interruption of logistics channel. COVID-19 had the greatest impact on freight development in Guangdong at that time. The negative impact value of freight volume of various forms of transportation reached the peak in February. The impact value of total freight volume is $-53.726 \%$, that of truck freight volume is $-65.155 \%$, that of water freight volume is $-31.232 \%$, that of air cargo volume is $-32.011 \%$, and that of pipeline freight volume is $-19.533 \%$. However, the impact of railway is positive, and the stagnation of other transportation promotes the actual value of railway freight volume to be higher than the predicted value, and the impact value is $15.829 \%$.

The second stage is the stage of entity conduction. The impact value of each subindex of Guangdong freight volume from March to May is reduced. This stage mainly focuses on the period from March to May 2020. The main impact of this stage is the uneven structure of the type and quantity of freight demand business in Guangdong Province and the short-term mismatch between supply and demand. The development of Guangdong's port freight industry has changed from explosive logistics demand in the early stage of the full resumption of manufacturing and circulation industries to the gradual emergence of real economic difficulties and the decline of logistics demand with the spread of the global epidemic.

The third stage is the policy digestion stage. This stage is mainly after May 2020; the state has issued relevant policies to support the recovery and development of the real economy and logistics industry, such as providing freeway and other measures to promote further recovery of freight. The role of policy has a certain lag and conductivity. The development of freight transportation in Guangdong Province is affected by the favorable policies and the recovery of logistics demand of the upstream manufacturing industry, which can be shown in turn in the postepidemic period. COVID-19's impact on freight development in Guangdong showed a gradual reduction. The risk points in this period mainly focus on the recovery of logistics industry, the scale of logistics investment, and the choice of new development mode.

5.2. Structural Characteristics. The impact of the epidemic on the development of freight transportation in Guangdong Province has structural characteristics. In the same period, the impact of the epidemic on the internal subbusiness sectors of freight transportation in Guangdong Province is different. The overall impact value of the epidemic on freight transportation was $-23.001 \%$, and the most affected mode was truck transportation $(-29.344 \%)$, followed by waterway transportation $(-11.296 \%)$ and air transportation 
TABLE 8: Average ratio of monthly freight (unit: \%).

\begin{tabular}{lcccccccccccc}
\hline & Jan & Feb & Mar & Apr & May & Jun & Jul & Aug & Sep & Oct & Nov & Dec \\
\hline$\overline{R_{j F}}$ & 7.378 & 6.364 & 7.560 & 8.032 & 8.251 & 8.357 & 8.529 & 8.571 & 8.794 & 9.095 & 9.304 & 9.766 \\
$\overline{R_{j R}}$ & 8.379 & 6.965 & 8.429 & 8.073 & 8.596 & 8.089 & 8.367 & 8.299 & 8.358 & 8.510 & 8.709 & 9.225 \\
$\overline{R_{j T}}$ & 7.117 & 6.221 & 7.484 & 7.989 & 8.229 & 8.341 & 8.594 & 8.634 & 8.837 & 9.220 & 9.369 & 9.965 \\
$\overline{R_{j W}}$ & 7.986 & 6.598 & 7.576 & 8.109 & 8.282 & 8.458 & 8.389 & 8.375 & 8.722 & 8.862 & 9.271 & 9.372 \\
$\overline{R_{j A}}$ & 7.715 & 6.537 & 7.762 & 8.051 & 8.340 & 8.311 & 8.470 & 8.470 & 8.678 & 8.922 & 9.163 & 9.582 \\
$\overline{R_{j P}}$ & 8.055 & 7.280 & 8.157 & 8.236 & 8.262 & 8.312 & 8.359 & 8.765 & 8.609 & 8.567 & 8.677 & 8.720 \\
\hline
\end{tabular}

Source: according to the calculation criteria.

TABle 9: COVID-19's impact of freight development in Guangdong Province (unit, million ton; \%).

\begin{tabular}{|c|c|c|c|c|c|c|c|c|c|}
\hline \multirow[b]{2}{*}{ Month } & \multicolumn{3}{|c|}{ Total freight volume } & \multicolumn{3}{|c|}{ Railway freight volume } & \multicolumn{3}{|c|}{ Truck freight volume } \\
\hline & $\begin{array}{l}\text { Actual } \\
\text { value }\end{array}$ & $\begin{array}{c}\text { Predictive } \\
\text { value }\end{array}$ & $\begin{array}{l}\text { Impact } \\
\text { degree }\end{array}$ & $\begin{array}{c}\text { Actual } \\
\text { value }\end{array}$ & $\begin{array}{l}\text { Predictive } \\
\text { value }\end{array}$ & $\begin{array}{l}\text { Impact } \\
\text { degree }\end{array}$ & $\begin{array}{l}\text { Actual } \\
\text { value }\end{array}$ & $\begin{array}{l}\text { Predictive } \\
\text { value }\end{array}$ & $\begin{array}{l}\text { Impact } \\
\text { degree }\end{array}$ \\
\hline Jan & 250.750 & 339.903 & -26.229 & 5.540 & 5.692 & -2.668 & 158.130 & 233.029 & -32.142 \\
\hline Feb & 135.680 & 293.208 & -53.726 & 5.480 & 4.731 & 15.829 & 70.980 & 203.705 & -65.155 \\
\hline Mar & 223.620 & 348.316 & -35.800 & 6.270 & 5.725 & 9.511 & 132.740 & 245.071 & -45.836 \\
\hline Apr & 267.320 & 370.044 & -27.760 & 5.980 & 5.484 & 9.048 & 170.170 & 261.582 & -34.946 \\
\hline May & 298.390 & 380.134 & -21.504 & 6.910 & 5.839 & 18.336 & 191.570 & 269.464 & -28.907 \\
\hline Jun & 308.350 & 385.032 & -19.916 & 6.780 & 5.495 & 23.387 & 204.060 & 273.113 & -25.284 \\
\hline Jul & 314.180 & 392.930 & -20.042 & 7.260 & 5.683 & 27.744 & 211.690 & 281.402 & -24.773 \\
\hline Aug & 329.530 & 394.878 & -16.549 & 6.650 & 5.637 & 17.964 & 215.540 & 282.716 & -23.761 \\
\hline Sep & 332.890 & 405.139 & -17.833 & 6.960 & 5.678 & 22.586 & 220.050 & 289.356 & -23.952 \\
\hline Oct & 349.210 & 419.023 & -16.661 & 6.360 & 5.780 & 10.029 & 237.200 & 301.893 & -21.429 \\
\hline Nov & 364.490 & 428.661 & -14.970 & 6.990 & 5.916 & 18.163 & 245.020 & 306.762 & -20.127 \\
\hline Dec & 373.100 & 449.955 & -17.081 & 6.490 & 6.266 & 3.568 & 256.410 & 326.298 & -21.418 \\
\hline $\begin{array}{l}\text { Total } \\
\text { impact }\end{array}$ & 4607.222 & 3547.510 & -23.001 & 77.67 & 67.927 & 14.343 & 2313.560 & 3274.392 & -29.344 \\
\hline
\end{tabular}

Source: according to the calculation criteria.

Table 10: COVID-19's impact of freight development in Guangdong Province (unit: million ton; \%).

\begin{tabular}{|c|c|c|c|c|c|c|c|c|c|}
\hline \multirow[b]{2}{*}{ Month } & \multicolumn{3}{|c|}{ Water freight volume } & \multicolumn{3}{|c|}{ Air cargo volume } & \multicolumn{3}{|c|}{ Pipeline freight volume } \\
\hline & $\begin{array}{l}\text { Actual } \\
\text { value }\end{array}$ & $\begin{array}{l}\text { Predictive } \\
\text { value }\end{array}$ & $\begin{array}{l}\text { Impact } \\
\text { degree }\end{array}$ & $\begin{array}{c}\text { Actual } \\
\text { value }\end{array}$ & $\begin{array}{l}\text { Predictive } \\
\text { value }\end{array}$ & $\begin{array}{l}\text { Impact } \\
\text { degree }\end{array}$ & $\begin{array}{l}\text { Actual } \\
\text { value }\end{array}$ & $\begin{array}{l}\text { Predictive } \\
\text { value }\end{array}$ & $\begin{array}{l}\text { Impact } \\
\text { degree }\end{array}$ \\
\hline Jan & 78.540 & 93.318 & -15.836 & 0.190 & 0.191 & -0.493 & 8.340 & 8.361 & -0.248 \\
\hline Feb & 53.020 & 77.100 & -31.232 & 0.110 & 0.162 & -32.011 & 6.080 & 7.556 & -19.533 \\
\hline Mar & 76.200 & 88.529 & -13.926 & 0.180 & 0.192 & -6.308 & 8.230 & 8.467 & -2.798 \\
\hline Apr & 82.360 & 94.757 & -13.083 & 0.180 & 0.199 & -9.662 & 8.640 & 8.549 & 1.065 \\
\hline May & 91.330 & 96.785 & -5.636 & 0.200 & 0.206 & -3.105 & 8.390 & 8.575 & -2.161 \\
\hline Jun & 87.890 & 98.840 & -11.079 & 0.210 & 0.206 & 2.087 & 9.410 & 8.628 & 9.068 \\
\hline Jul & 86.630 & 98.033 & -11.632 & 0.200 & 0.210 & -4.591 & 8.410 & 8.677 & -3.075 \\
\hline Aug & 95.000 & 97.869 & -2.932 & 0.200 & 0.210 & -4.593 & 12.140 & 9.098 & 33.432 \\
\hline Sep & 94.440 & 101.925 & -7.344 & 0.240 & 0.215 & 11.745 & 11.200 & 8.936 & 25.332 \\
\hline Oct & 93.680 & 103.560 & -9.540 & 0.220 & 0.221 & -0.367 & 11.750 & 8.893 & 32.131 \\
\hline Nov & 99.080 & 108.343 & -8.550 & 0.220 & 0.227 & -2.994 & 13.180 & 9.007 & 46.332 \\
\hline Dec & 98.400 & 109.513 & -10.148 & 0.230 & 0.237 & -3.017 & 11.580 & 9.051 & 27.948 \\
\hline $\begin{array}{l}\text { Total } \\
\text { impact }\end{array}$ & 1036.570 & 1168.572 & -11.296 & 2.380 & 2.475 & -3.838 & 117.350 & 103.797 & 13.057 \\
\hline
\end{tabular}

Source: according to the calculation criteria.

$(-3.838 \%)$. At the beginning of the outbreak, the railway operation remained sustainable. Due to the suspension of road transport enterprises, a large number of goods were transferred to railway transportation. Pipeline transportation can be carried out without people. The epidemic has little impact on its production and operation. Therefore, the impact of COVID-19 on the railway transportation and pipeline transportation is positive. The influence values were 14.343 and 13.057, respectively. In summary, the development structure of freight transport in Guangdong has been characterized by structural development under the influence of COVID-19. 


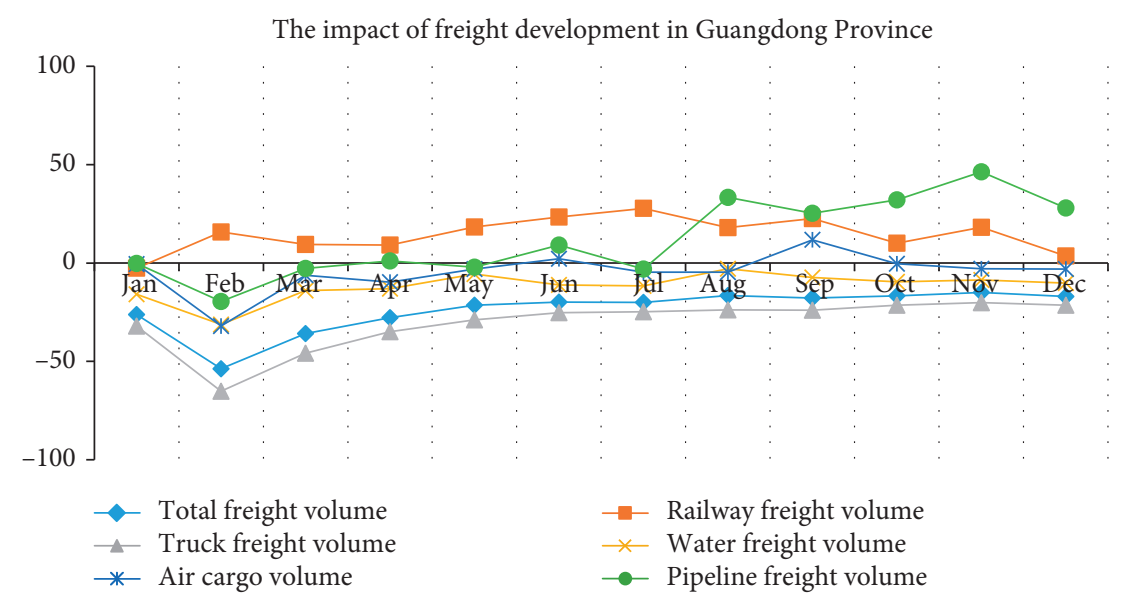

FIgUre 1: The impact of freight development in Guangdong Province.

5.3. Characteristics of Solid Conduction. Freight industry is a derivative industry. The demand of freight industry is mainly affected by the secondary industry and commodity circulation industry and is mainly affected by manufacturing industry, import and export trade, domestic trade, and manufacturing industry. As an auxiliary industry of the national economy, freight industry is an important support for the development of industrial economy. The crisis of the freight industry will be transmitted in reverse, resulting in damage to the real economy. During the epidemic period, due to traffic control, road restrictions, blocked logistics channels, staff unable to rework and resume production on time, and unsatisfied conditions for resumption of production, some freight enterprises were unable to provide normal freight service, which affected the resumption of some industrial enterprises and could not guarantee the logistics of raw materials and finished products.

\section{Research on the Related Factors of Freight Development in Guangdong Province}

The grey prediction model GM $(1,1)$ can scientifically measure the impact of COVID-19 on the development of freight transport in Guangdong. From the perspective of system theory, the development of freight transportation in Guangdong Province is the output of logistics system and the product of adapting to the economic environment and regional development of Guangdong Province. Therefore, in order to explore the countermeasures of the development of freight transportation in Guangdong Province in the postepidemic period, we should also analyze the environmental factors. To sum up, this paper will use the grey correlation model to study the related factors of freight development in Guangdong Province.

6.1. Construction of the Index System. Scholars in the study of freight development factors divide them mainly into the regional economic factors, logistics environmental factors, and industrial factors for quantitative index selection; this paper, considering the scientificity, rationality, comprehensiveness, and comparability of the index construction, divides the related factors of the freight development of Guangdong Province into economic factors, transportation factors, science and technology factors, and policy factors, as shown in Table 11 .

6.2. Calculation of Grey Correlation Degree of Influencing Factors. Based on the freight development of Guangdong Province from 2011 to 2019, total freight volume, railway freight volume, truck freight volume, water freight volume, air cargo volume, and pipeline freight volume are the main factor sequence data of the system. The historical data of $\mathrm{X}_{11}-\mathrm{X}_{46}$ index factors are regarded as subfactor series data, and the grey correlation resolution coefficient is 0.5 based on experience. The data involved are from the public data of the Guangdong Statistical Yearbook in 2013-2019. The grey correlation degree of influencing factors of freight development in Guangdong Province is calculated as given in formulas (24)-(26) and $\operatorname{AVG} \gamma_{0 i}=\operatorname{avg}\left(\gamma_{0 i F}+\gamma_{0 i R}+\right.$ $\left.\gamma_{0 i T}+\gamma_{0 i W}+\gamma_{0 i A}+\gamma_{0 i P}\right)$, and the calculation results are shown in Tables 12-14.

The closer the value to 1 , the higher the correlation between the self-factor sequence data and the main factor sequence data. According to the calculation results of correlation degree of Tables 12-14, AVG $R_{042}>$ AVG $R_{044}>$ AVG $R_{014}>$ AVG $R_{041}=\mathrm{AVG} R_{046}>\mathrm{AVG} R_{023}>\mathrm{AVG}$ $R_{011}>\mathrm{AVG} R_{045}>\mathrm{AVG} R_{015}>\mathrm{AVG} R_{024}>\mathrm{AVG} R_{021}>\mathrm{AVG}$ $R_{031}>\mathrm{AVG} R_{043}>\mathrm{AVG} R_{043}>\mathrm{AVG} R_{016}>\mathrm{AVG} R_{017}>\mathrm{AVG}$ $R_{012}=\mathrm{AVG} R_{022}>\mathrm{AVG} R_{032}>\mathrm{AVG} R_{013}>\mathrm{AVG} R_{025}$; there are 15 factors with $\mathrm{AVG} R_{0 i}$; there are 15 factors with $\mathrm{AVG} R_{0 i}$ greater than or equal to 0.8 , indicating that the vast majority of factors are highly related to the development of freight transportation in Guangdong Province, including operating mileage of railway, tonnage of trucks, disposable income, deposit balance of financial institutions, number of employees in transportation, warehousing and postal industry, transport aircraft, R\&D personnel, GDP, mileage of oil pipeline, total retail sales of consumer goods, financial expenditure on education, Internet broadband access users, general budget revenue, tonnage of cargo ships, and total 
TABLE 11: Index system of influencing factors of freight development in Guangdong Province.

\begin{tabular}{|c|c|c|c|}
\hline First level indicators & Second level indicators & Variable & Characteristic \\
\hline \multirow{7}{*}{ Regional economy factors } & Gross domestic product & $X_{11}$ & $\begin{array}{c}\text { Positive } \\
\text { correlation }\end{array}$ \\
\hline & Proportion of added value of secondary industry & $X_{12}$ & $\begin{array}{l}\text { Positive } \\
\text { correlation }\end{array}$ \\
\hline & Total investment in fixed assets & $X_{13}$ & $\begin{array}{l}\text { Positive } \\
\text { correlation }\end{array}$ \\
\hline & Per capita disposable personal income & $X_{14}$ & $\begin{array}{l}\text { Positive } \\
\text { correlation }\end{array}$ \\
\hline & Total retail sales of social consumption & $X_{15}$ & $\begin{array}{l}\text { Positive } \\
\text { correlation }\end{array}$ \\
\hline & Total imports and exports & $X_{16}$ & $\begin{array}{l}\text { Positive } \\
\text { correlation }\end{array}$ \\
\hline & $\begin{array}{l}\text { Balance of domestic and foreign currency deposits of financial } \\
\text { institutions }\end{array}$ & $X_{17}$ & $\begin{array}{l}\text { Positive } \\
\text { correlation }\end{array}$ \\
\hline \multirow{5}{*}{ Science and technology factors } & Number of Internet broadband access users & $X_{21}$ & $\begin{array}{l}\text { Positive } \\
\text { correlation }\end{array}$ \\
\hline & Internal expenditure of $\mathrm{R} \& \mathrm{D}$ funds & $X_{22}$ & $\begin{array}{l}\text { Positive } \\
\text { correlation }\end{array}$ \\
\hline & Number of employees of R\&D & $X_{23}$ & $\begin{array}{l}\text { Positive } \\
\text { correlation }\end{array}$ \\
\hline & Education expenditure & $X_{24}$ & $\begin{array}{l}\text { Positive } \\
\text { correlation }\end{array}$ \\
\hline & Expenditure on science and technology & $X_{25}$ & $\begin{array}{l}\text { Positive } \\
\text { correlation }\end{array}$ \\
\hline \multirow{2}{*}{ Government policy factors } & Revenue & $X_{31}$ & $\begin{array}{l}\text { Positive } \\
\text { correlation }\end{array}$ \\
\hline & Transportation expenditure & $X_{32}$ & $\begin{array}{l}\text { Positive } \\
\text { correlation }\end{array}$ \\
\hline \multirow{6}{*}{$\begin{array}{l}\text { Transportation environment } \\
\text { factors }\end{array}$} & Number of employees in transportation, storage, and post industry & $X_{41}$ & $\begin{array}{l}\text { Positive } \\
\text { correlation }\end{array}$ \\
\hline & Length of railroad lines in service & $X_{42}$ & $\begin{array}{l}\text { Positive } \\
\text { correlation }\end{array}$ \\
\hline & Net tonnage of carrying vessel & $X_{43}$ & $\begin{array}{l}\text { Positive } \\
\text { correlation }\end{array}$ \\
\hline & Tonnage of truck & $X_{44}$ & $\begin{array}{l}\text { Positive } \\
\text { correlation }\end{array}$ \\
\hline & Oil pipeline mileage & $X_{45}$ & $\begin{array}{l}\text { Positive } \\
\text { correlation }\end{array}$ \\
\hline & Transport plane & $X_{46}$ & $\begin{array}{l}\text { Positive } \\
\text { correlation }\end{array}$ \\
\hline
\end{tabular}

TABLE 12: Grey correlation results of freight development in Guangdong Province (1).

\begin{tabular}{lccccccc}
\hline Variable & $X_{11}$ & $X_{12}$ & $X_{13}$ & $X_{14}$ & $X_{15}$ & $X_{16}$ & $X_{17}$ \\
\hline$\gamma_{0 i F}$ & 0.896 & 0.762 & 0.807 & 0.925 & 0.900 & 0.774 & 0.818 \\
$\gamma_{0 i R}$ & 0.747 & 0.916 & 0.689 & 0.806 & 0.737 & 0.903 & 0.708 \\
$\gamma_{0 i T}$ & 0.894 & 0.747 & 0.816 & 0.904 & 0.897 & 0.758 & 0.829 \\
$\gamma_{0 i W}$ & 0.930 & 0.752 & 0.798 & 0.903 & 0.917 & 0.761 & 0.824 \\
$\gamma_{0 i W}$ & 0.921 & 0.726 & 0.798 & 0.871 & 0.884 & 0.733 & 0.848 \\
$\gamma_{0 i A}$ & 0.838 & 0.866 & 0.740 & 0.924 & 0.823 & 0.879 & 0.773 \\
AVG $\gamma_{0 i}$ & 0.871 & 0.795 & 0.775 & 0.889 & 0.860 & 0.801 & 0.800 \\
\hline
\end{tabular}

Source: according to the calculation criteria.

import and export, which are most closely related to the development of freight transportation in Guangdong Province, ranking in the top 15 with the correlation degree greater than 0.8 . The relevance degree of the added
TABLE 13: Grey correlation results of freight development in Guangdong Province (2).

\begin{tabular}{lccccccc}
\hline Variable & $X_{21}$ & $X_{22}$ & $X_{23}$ & $X_{24}$ & $X_{25}$ & $X_{31}$ & $X_{32}$ \\
\hline$\gamma_{0 i F}$ & 0.850 & 0.823 & 0.890 & 0.870 & 0.586 & 0.848 & 0.816 \\
$\gamma_{0 i R}$ & 0.749 & 0.706 & 0.779 & 0.744 & 0.599 & 0.712 & 0.806 \\
$\gamma_{0 i T}$ & 0.848 & 0.819 & 0.882 & 0.867 & 0.590 & 0.859 & 0.824 \\
$\gamma_{0 i W}$ & 0.885 & 0.825 & 0.933 & 0.899 & 0.576 & 0.858 & 0.770 \\
$\gamma_{0 i W}$ & 0.917 & 0.831 & 0.912 & 0.913 & 0.558 & 0.877 & 0.743 \\
$\gamma_{0 i A}$ & 0.831 & 0.764 & 0.881 & 0.824 & 0.579 & 0.781 & 0.785 \\
AVG $\gamma_{0 i}$ & 0.847 & 0.795 & 0.880 & 0.853 & 0.582 & 0.823 & 0.791
\end{tabular}

Source: according to the calculation criteria.

value of the secondary industry in the proportion of GDP is greater than 0.7, and its closeness with the freight development of Guangdong Province cannot be ignored. The relevance degree of science and technology financial 
TABLE 14: Grey correlation results of freight development in Guangdong Province (3).

\begin{tabular}{lcccccc}
\hline Variable & $X_{41}$ & $X_{42}$ & $X_{43}$ & $X_{44}$ & $X_{45}$ & $X_{46}$ \\
\hline$\gamma_{0 i F}$ & 0.916 & 0.947 & 0.808 & 0.915 & 0.908 & 0.902 \\
$\gamma_{0 i R}$ & 0.807 & 0.785 & 0.878 & 0.790 & 0.790 & 0.777 \\
$\gamma_{0 i T}$ & 0.894 & 0.923 & 0.789 & 0.901 & 0.903 & 0.887 \\
$\gamma_{0 i W}$ & 0.897 & 0.919 & 0.803 & 0.930 & 0.894 & 0.935 \\
$\gamma_{0 i W}$ & 0.864 & 0.876 & 0.767 & 0.906 & 0.829 & 0.942 \\
$\gamma_{0 i A}$ & 0.950 & 0.922 & 0.870 & 0.911 & 0.885 & 0.883 \\
AVG $\gamma_{0 i}$ & 0.888 & 0.895 & 0.819 & 0.892 & 0.868 & 0.888 \\
\hline
\end{tabular}

Source: according to the calculation criteria.

expenditure is only 0.582 , and its relevance with the freight development of Guangdong Province can be ignored.

6.3. Analysis of Grey Correlation Results. By using the grey correlation analysis method, we can objectively and reasonably reflect the influence degree of relevant influencing factors on the freight development of Guangdong Province and provide a quantifiable research perspective for the analysis of the relationship between regional economic factors, scientific and technological environment factors, government policy factors, transportation environment factors, and the freight development of Guangdong Province:

(1) The regional economic environment plays an important role in the freight development Guangdong Province.

The average value of the six factors of regional economy ( $\mathrm{AVG} R_{01 i}$ ) is 0.827 , and the value of four factors is greater than 0.8 , which reflects that the economic environment is closely related to the freight development of Guangdong Province. The regional economic environment represents the demand of the freight market in the port market and reflects the impact of the economic environment on the demand of the port freight market; it also reflects the industrial transmission effect of the logistics industry affected by the real economy.

(2) The development of freight transportation in Guangdong Province should pay attention to the environmental factors of science and technology.

The value of science and technology environment factor (AVG $R_{02 i}$ ) is 0.791 . There is a certain degree of correlation between R\&D personnel and the level of regional science and technology in Guangdong Province and the development of freight transportation in Guangdong Province, which means that the promotion and development of information technology have greatly promoted the development of freight transportation in Guangdong Province. R\&D practitioners reflect the information technology talents, education expenditure reflects the strength of regional talent cultivation, and the amount of Internet broadband access reflects the basic environment of science and technology. The above three factors are greater than 0.8 , which shows that the development of freight transportation in Guangdong Province is constrained by the basic conditions of the development of information technology and the cultivation of information talents. However, the government's financial expenditure on science and technology has no direct correlation with the freight development of Guangdong Province, and its correlation coefficient is only 0.582 .

(3) Government policy factors guide freight development in Guangdong Province.

The value of government policy factor (AVG $\left.R_{03 i}\right)$ is 0.807 . The government's financial capacity and the intensity of transportation expenditure are closely related to the development of freight transportation in Guangdong Province. The amount of government's financial revenue and the intensity of transportation expenditure are helpful to improve the conditions of transportation infrastructure in Guangdong Province.

(4) The transportation environment factors directly affect the development of freight in Guangdong Province.

The value of environmental factors of transportation (AVG $R_{04 i}$ ) is 0.875 . The development of freight transportation in Guangdong Province is closely related to environmental factors of transportation. The correlation degree between the environmental factors of transportation and the freight development of Guangdong Province is greater than 0.8 . The operating mileage of railway and oil pipeline reflects the overall infrastructure of freight industry. The number of employees in transportation, warehousing, and postal industry reflects the human resource factors of logistics industry. The number of trucks, ships, and aircraft reflects the basic equipment conditions of logistics. The above indicators are closely related to the freight development of Guangdong Province.

\section{Conclusions and Suggestions}

This paper makes a quantitative study on the development trend of freight transport in Guangdong from the perspective of freight volume. However, the research needs to be further expanded to fully reflect the overall situation of freight development in Guangdong Province, such as the study of freight market price factors and the change of supply-demand relationship. The empirical study shows the COVID-19 has a certain impact on the freight development of Guangdong, which has the following characteristics: stage characteristics, structural characteristics, and physical transmission characteristics; the total freight volume of Guangdong is affected by $-23.001 \%$, and the truck 
transportation is affected by $-29.344 \%$, with $-11.296 \%$ for water transportation and $-3.838 \%$ for air transportation. Due to the continuity of transportation and the substitution for other transportation modes, the freight volume of railway and pipeline transportation is affected by $14.343 \%$ and $13.057 \%$, respectively.

To further explore the abate measures of COVID-19 impact on Guangdong's freight development, the grey correlation model is introduced to study the correlation factors of freight development of Guangdong Province. This paper selects four factors including regional economic environment, science and technology environment, government policy, and transportation and logistics environment, covering 20 subfactors. Through the research, it is found that the average correlation degree of the four factors is greater than 0.7 and the order of correlation degrees is as follows: transportation and logistics environment factors, government policy factors, and science and technology environment factors.

Through the research on the related factors of freight development of Guangdong Province, this paper puts forward the following measures to promote the freight development in Guangdong Province in the postepidemic era: first, pay attention to improving the freight infrastructure equipment in Guangdong Province, improve the efficiency of infrastructure equipment operation, and improve the connection ability of transportation modes, such as sea rail combined transportation, sea air combined transportation, and sea land combined transportation. Second, the government continues to invest in transportation infrastructure and introduces relevant measures, such as reducing and exempting tolls, operating taxes, and so on. Third, strengthen the linkage between freight development and economy, pay attention to the trend of economic development, and timely adjust the strategy of freight development and operation. Fourth, pay attention to strengthening the construction and application of information technology and intelligent technology in freight operation and improve the intelligent and digital degree of freight operation process.

\section{Data Availability}

The data used to support the findings of the study and related data are available from all the authors upon request.

\section{Conflicts of Interest}

The authors declare there are no conflicts of interest regarding the publication of this paper.

\section{Acknowledgments}

This research was financially supported by the 2021 School Level Scientific Research Project of Guangzhou Huashang College (Grant no.2021HSDS09); 2020 Project of Guangzhou Philosophy and Social Science Development Plan "Research on the Influence Mechanism of Guangzhou Residents' Physical Consumption and Experience Consumption on Happiness" (Grant no .2020GZGJ210); Construction of Guangdong Provincial Characteristic Specialty-
Construction of Logistics Management Specialty in 2019 (Grant no. HS2019CXQX04); Humanities and Social Sciences Research Projects of Universities in Guangdong Province "Construction of Key Disciplines in Business Administration" (Grant no. 2015WTSCX126); "Key Discipline Construction of Enterprise Management" of Guangzhou Huashang University (Grant no. 2020HSXK05); School Level Quality Engineering "Supply Chain Management Offline First Class Course" of Guangzhou Huashang University (Grant no. HS2020ZLGC15); and "Key Discipline: International Business Construction and Development" (HS2019CXQX17).

\section{References}

[1] M. Li and S. Zhang, "Research on dynamic industrial linkage and impact effect of logistics industry," World Scientific Research Journal, vol. 5, no. 7, 2019.

[2] Y. A. Bolumole, D. J. Closs, and F. A. Rodammer, "The economic development role of regional logistics hubs: a crosscountry study of interorganizational governance models," Journal of Business Logistics, vol. 36, no. 2, 2015.

[3] J. Zhang and L. Chen, "The industrial relations of logistics industry-based on China's 2010 input-output table," Modern Economy, vol. 5, no. 12, 2014.

[4] Y. Su, Q. Jin, P. Yang, Q. Jiang, and G.-W. Weber, "A supply chain-logistics super-network equilibrium model for urban logistics facility network optimization," Mathematical Problems in Engineering, vol. 2019, Article ID 5375282, 12 pages, 2019.

[5] S. Tang, S. Xu, and J. Gao, "An optimal model based on multifactors for container throughput forecasting," KSCE Journal of Civil Engineering, vol. 23, no. 9, 2019.

[6] X. Wang, Y. A. N. Ying, J. Feng, and J. Xiang, "Research on the demand forecasting method of sichuan social logistics based on positive weight combination," Canadian Social Science, vol. 14, no. 6, 2018.

[7] T. Liu, S. Li, and S. Wei, "Forecast and opportunity analysis of cold chain logistics demand of fresh agricultural products under the integration of beijing, tianjin and hebei," Open Journal of Social Sciences, vol. 5, no. 10, 2017.

[8] D. Knoll, M. Prüglmeier, and G. Reinhart, "Predicting future inbound logistics processes using machine learning," Procedia CIRP, vol. 52, pp. 145-150, 2016.

[9] D. Yang, "Logistics demand forecast model for port import and export in coastal area," Journal of Coastal Research, vol. 103, no. sp1, 2020.

[10] J. Bruzda, "Multistep quintile forecasts for supply chain and logistics operations: bootstrapping, the GARCH model and quintile regression based approaches," Central European Journal of Operations Research, vol. 28, no. 1, 2020.

[11] X. Li and Li Guo, "Research on the driving force of the regional economy to the development of ocean port shipping based on multiple regression analysis," Journal of Coastal Research, vol. 111, no. 1, 2020.

[12] H. K. Kim and W. Chang, "Development of a cost forecasting model for air cargo service delay due to low visibility," Sustainability, vol. 11, no. 16, 2019.

[13] J. Farhan and G. P. Ong, "Forecasting seasonal container throughput at international ports using SARIMA models," Maritime Economics \& Logistics, vol. 20, no. 1, 2018.

[14] Y. Xiao, S. Wang, M. Xiao, J. Xiao, and Y. Hu, "The analysis for the cargo volume with hybrid discrete wavelet modeling," 
International Journal of Information Technology \& Decision Making, vol. 16, no. 3, 2017.

[15] B.-W. Ko and D.-J. Kim, "Analysis of container shipping market using multivariate time series models," Journal of Korea Port Economic Association, vol. 35, no. 3, pp. 61-72, 2019.

[16] B. Hong, R. Song, "Forecast of railway freight ton-kilometers based on the UBGPM-markov model," Advanced Materials Research, vol. 3470, pp. 2199-2202, 2014.

[17] W. Li, J. Dai, Y. Xiao, S. Yang, and C. Song, "Estimating waterway freight demand at Three Gorges ship lock on Yangtze River by back propagation neural network modeling," Maritime Economics \& Logistics, vol. 2020, pp. 1-27, 2020.

[18] M. I. Asborno and S. Hernandez, "Using data from a state travel demand model to develop a multi-criteria framework for transload facility location planning," Transportation Research Record, vol. 2672, no. 9, pp. 12-23, 2018.

[19] S. Tadić, M. Krstić, V. Roso, and N. Brnjac, "Planning an intermodal terminal for the sustainable transport networks," Sustainability, vol. 11, no. 15, 2019.

[20] Z. Zhang, "Research on the carbon emission diving factors and forecasts of logistics industry in the bohai rim economic zone based on the theory of grey system," Journal of Management \& Decision Sciences, vol. 3, no. 1, 2020.

[21] H. Zhang, J. Zhu, and L. Zhou, "Research on logistics demand forecasting and transportation structure of beijing based on grey prediction model," Science Journal of Applied Mathematics and Statistics, vol. 3, no. 3, 2015.

[22] E. Suryani and S.-Y. Chou, "Chih-Hsien Chen Dynamic simulation model of air cargo demand forecast and terminal capacity planning," Simulation Modelling Practice and Theory, vol. 28, 2012.

[23] Y. Huang, "Development prediction of logistics industry in Henan province and its dynamic analysis," Grey Systems: Theory and Application, vol. 4, no. 2, 2014.

[24] C.-N. Wang, H.-K. Nguyen, R.-Y. Liao, and E. J. Macías, "Partner selection in supply chain of vietnam's textile and apparel industry: the application of a hybrid DEA and GM (1, 1) approach," Mathematical Problems in Engineering, vol. 2017, Article ID 7826840, 16 pages, 2017. 